\title{
A Novel Indirect Parabolic Solar Cooker
}

\author{
Omotoyosi O. Craig ${ }^{1}$, Robert T. Dobson ${ }^{2}$ and Wikus van Niekerk ${ }^{3}$ \\ 1. Solar Thermal Energy Research Group, Stellenbosch University, Stellenbosch 7602, South Africa \\ 2. Mechanical and Mechatronics Engineering Department, Stellenbosch University, Stellenbosch 7602, South Africa \\ 3. Centre for Renewable and Sustainable Energy Studies, Stellenbosch University, Stellenbosch 7602, South Africa
}

\begin{abstract}
The continuous increase in global demand and cost of electricity are some of the reasons that solar cooking has received much attention recently. Another factor which has also contributed to the acceptance of solar cookers is global campaigns against actions that contribute to climate change. Various types of solar cookers are currently in existence, these are box, panel and parabolic cookers. Some solar cookers only function when the cooking section is placed under direct sunshine, while others have been modified to cook without directly exposing their cooking section to the sun. Most solar cookers face similar challenges, and these include, exposure of users to sun, inability to function at night or when there is no sunshine, low utilization efficiency and technical complexities. This report presents an indirect parabolic cooker that eliminates the identified solar cooker challenges. The cooker uses a parabolic reflector to focus the sun rays to a frustum shaped receiver that was placed at its focus. The cooker has an insulated cooking/heat storage tank which was separated from the dish and cavity receiver system. The heat transfer fluid was distributed through the system with the aid of high temperature flexible hoses. Several cooking tests including water boiling and pancake baking were done, an extensive analysis of cooking based on the international testing procedures for solar cookers was also carried out. This solar cooker had a utilization efficiency of $39 \%$, an overall calculated exergy efficiency of $0.05 \%$ and an average characteristic boiling time of approximately 13 minutes $/ \mathrm{kg}$. The manufactured solar cooker in this study was used for family cooking.
\end{abstract}

Key words: Parabolic dish, cavity receiver, indoor cooking, utilization efficiency.

\section{Introduction}

Several energy sources have been used for cooking at various locations on earth. Although, most rural areas in sub-Saharan Africa rely predominantly on wood for cooking [1], places like SA (South Africa) rely on electricity as the major source of energy for cooking as shown in Fig. 1, where electricity is the major source of heat for cooking in SA.

While the use of wood for cooking may lead to deforestation, high dependence on electricity for cooking also contributes to increase in the energy demand thereby leading to insufficient supply, if not well managed.

The need to find other sources of cooking is therefore important and solar energy is a realistic option [2].

Corresponding author: Omotoyosi O. Craig, research engineer, research fields: solar energy, solar thermal energy processes and energy innovations.
Solar energy is the most abundant of all the renewable energy, as all energy sources generate their power from the sun. Sunshine is free and always available, and if all the power from the sun can be harnessed, then all of the human energy need would be met. An important method in which direct energy from the sun is being used is through solar cooking technology, which ranges from very simple ones to very sophisticated ones in terms of technicalities [3].

Any system that makes use of solar energy to boil or pasteurize water or cook food can be referred to as a solar cooker [4]. Existing solar cookers have been classified based on their shapes, reflection techniques or their cooking methods. Panwar et al. [5] presented a comprehensive classification based on shape and reflection technique as shown in Fig. 2.

Direct solar cookers are the types that work with the cooker and the food directly exposed to sunshine, while, indirect solar cookers are the types that eliminate the exposure of users to the sun. In indirect solar cooking, 


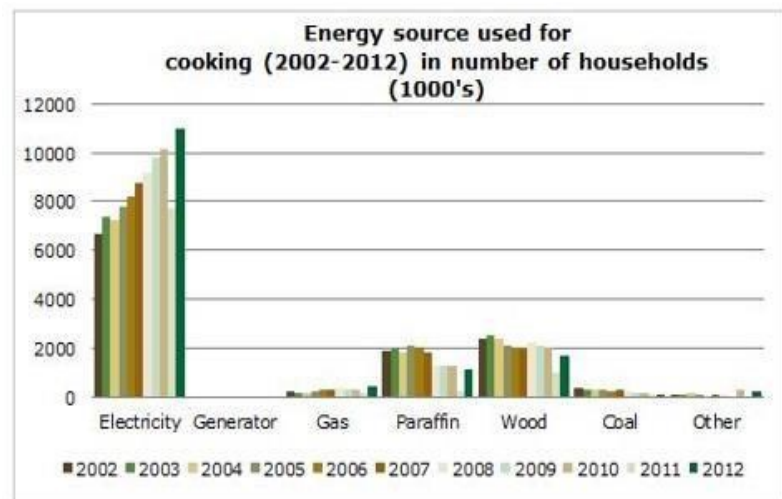

Fig. 1 Energy sources for cooking in South Africa [2].

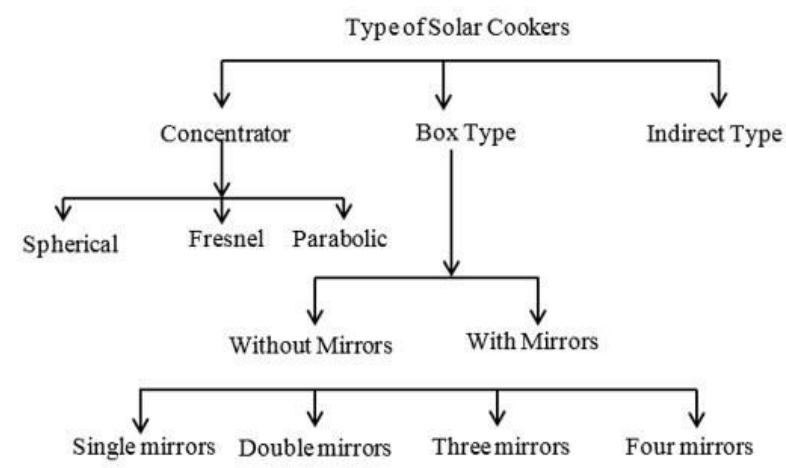

Fig. 2 Classification of solar cookers [5].

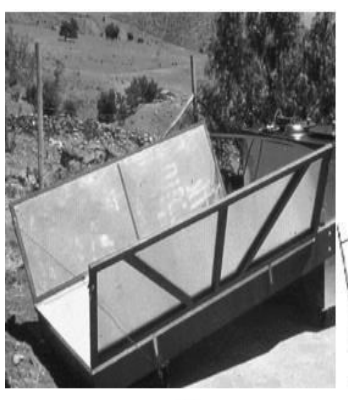

(a)

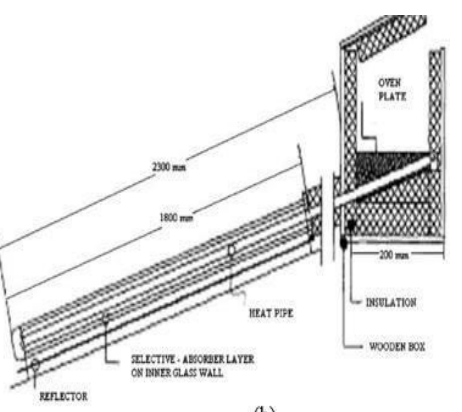

(b)
Fig. 3 Indirect solar cookers: (a) flat plate in Chile [6]; (b) evacuated tube [7].

the solar collector that receives direct solar radiation is separated from the cooking section. The heat is often transferred between the two parts using heat transfer mediums like steam, paraffin or various types of oil [4]. Some indirect solar cookers are available commercially but the adoption and deployment has been low due to complexities, low efficiencies and cost. The commercially existing ones have been based on siphon technology using glass or evacuator tube technology as seen in Figs. 3a and 3b respectively.
Fig. 3a is an outdoor cooker made by Schwarzer and da Silva [6] for a primary school in Northern Chile. The heat transfer medium is groundnut oil which operates in a cycle. The pot is fixed, thereby causing difficulties in cleaning and thus compromises the hygiene standards for cooking. The cooker also does not function well in the absence of direct sunshine [6]. Fig. 3b was reported by Muthusivagami et al. [7] to have been manufactured by Balzar. It uses sets of heat pipes placed in a vacuum tube as heat transfer medium and the cooking is done in an insulated oven done on the right side. This technique for solar cooking was welcomed because it required no solar tracking. The mass deployments of this solar cooker type were halted because it is fragile, expensive and high-tech.

\section{Theory and Design}

The design presented in this report uses an indirect parabolic dish technology. The concentrator used was a $2 \mathrm{~m}$ parabolic shaped satellite dish which was covered with aluminum foil. The maximum desired output temperature was $220^{\circ} \mathrm{C}$, the system was active, as it uses a refurbished motor car pump to circulate the heat-transfer fluid through the whole system.

A tracking system was developed as a modification to the model by Roth et al. [8], using the automatic positioner of Prinsloo et al. [9]. The error calculations and actual parabolic reflections were done using equations developed by Stine and Geyer [10].

It was assumed in the design that the rays of the sun are parallel to the collector dish in accordance with the model developed by Stine and Geyer [10] for error analysis, and the error equations were developed in terms of rim angles. The developed equations were used to find the slope errors in the sun's rays, and this was solved simultaneously with tracking errors to analyze the spread of the reflected rays of the sun on the focus of the dish. The result of this analysis shows the size of image formed at the focus of the dish and we used that to determine the minimum and maximum size of the receiver aperture. A step by step analysis 
developed by Craig [4] shown in Fig. 4 was followed.

The minimum entry aperture width for the receiver was determined using the procedure shown in Fig. 4 and modified Equation becomes

$$
W_{n}=2 p\left(n \frac{\sigma_{\text {total }}}{2}\right) \cos \varphi
$$

where, $W_{n}$ is the width of the receiver aperture, $\sigma_{\text {total }}$ is the total tracking error while $\varphi$ is the rim angle, $n$ is the number of days from January and $p$ is the parabolic radius of the reflector dish. A frustum shaped conical receiver was then manufactured based on Eq. (1) with copper tube of $40 \mathrm{~m}$ length and $10 \mathrm{~mm}$ diameter. The design was covered with a stainless steel bucket, and the set up was insulated with ceramic wool as shown in Fig. 5.

Fig. 6 shows the top part of the storage tank, the tank material is mild steel and it has a volumetric capacity of 40 liters. An inside depression was made in the tank to provide a base for the spiral cooking section, and also eliminate the challenge of the cooking pot hygiene experience by Schwarzer and da Silva [6]. The spiral tube cooking head method was recently confirmed by Craig and Dobson [11] to be a preferred method for cooking when using indirect type solar cooking technology. The whole setup was insulated with ceramics wool of $60 \mathrm{~mm}$ thickness.

The receiver with the parabolic dish was connected to the storage system using high temperature hoses and

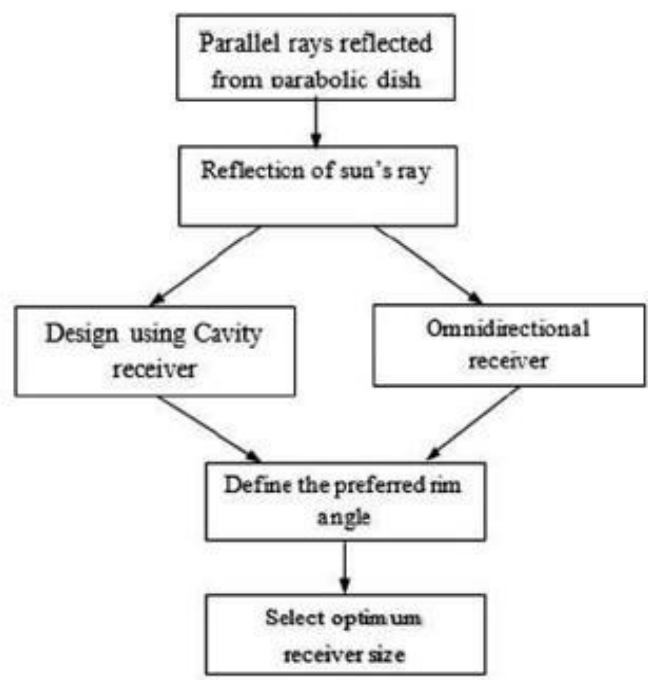

Fig. 4 Parabolic reflector optical analysis [4].
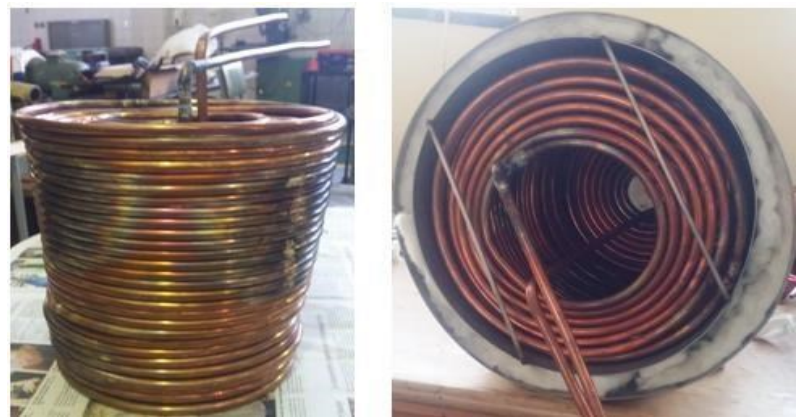

Fig. 5 Conical receiver.

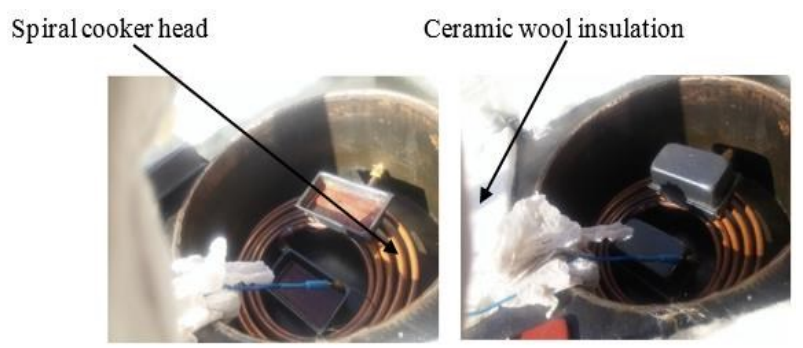

Fig. 6 Storage and cooking system.

the heat transfer fluid used was shell oil. The system set up was mounted on the heat transfer laboratory roof top at Stellenbosch University $33^{\circ} 55^{\prime} 41.10^{\prime \prime} \mathrm{S}$, $18^{\circ} 51^{\prime} 58.80^{\prime \prime} \mathrm{E}$ and $119 \mathrm{~m}$ height above sea level. An overall heat transfer analysis of the system was performed and two parameters that contributed most to the overall useful efficiency were identified as the optical efficiency and receiver losses.

\section{Experimental Set up}

Experiments were set up with the aim of obtaining the parameters by which the system's cooking power and efficiencies could be calculated. Fig. 7 shows the solar collection system, where the dish and receiver were mounted on a tracker stand, was placed outside. The pump circulates the heat transfer fluid throughout the system through the high temperature hoses.

Several cooking experiments were performed to understand the optimal working conditions of the parabolic cooker. The analysis and cooking tests were based on the international testing procedures for solar cookers as reviewed by Funk [12]. The model for the analysis of cooking section was done by incorporating internal energy and heat losses into models developed by El-Kassaby [13], Amer [14] and Kimambo [15]. 

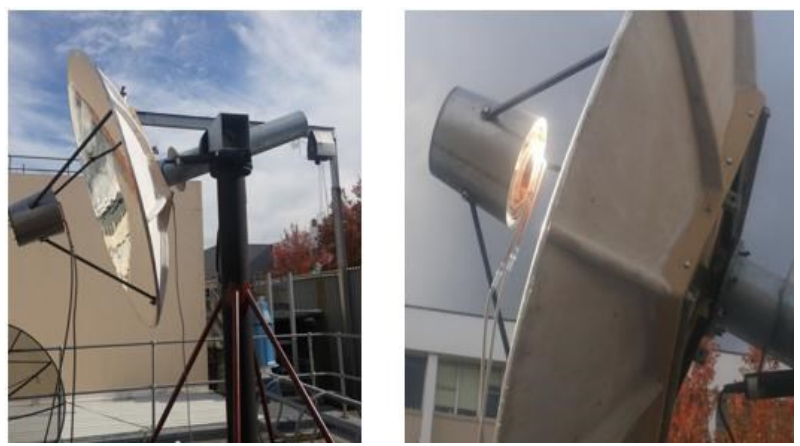

Fig. 7 Parabolic dish and conical receiver set up.

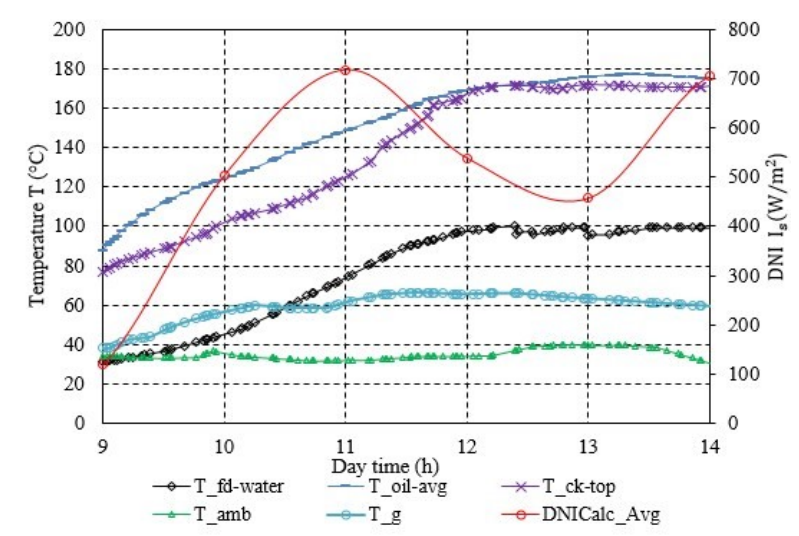

Fig. 8 Boiling of water on 12 June 2015.

\section{Experimental Results}

The optimal test of performance for a solar cooker is often based on its water boiling characteristics, this is because most types of food cooking involve heating of water. Several experiments were performed from April through June, 2015. Fig. 8 shows the result of a specific boiling experiment on 12th June with average hourly DNI of $570 \mathrm{~W} / \mathrm{m}^{2}$. The water boiling took place between 8 a.m. to 4 p.m. The pot size used for the experiment was $200 \times 100 \mathrm{~mm}$ holding water of $4 \mathrm{~kg}$ mass. The pot was placed on the spiral cooker in the depressed part of the storage tank. The water boiled after 4 hours at around 12.30 p.m. as shown in Fig. 8.

The initial oil temperature was at $60^{\circ} \mathrm{C}$ as the storage retained heat from the previous day's experiment. The initial difference between the cooking top temperature $\mathrm{T}_{\text {ck-top }}$ and the average oil temperature $\mathrm{T}_{\text {oil-avg }}$ in the tank was as a result of an initial resistance of the spiral cooking head material (copper resistance). $T_{g}$ is the temperature of the air between the boiled water and the pot covers. It took 3 hours for the average temperature in the tank and the spiral cooking head to reach equilibrium; a high $\mathrm{T}_{\mathrm{g}}$ was found to promote high convection. $\mathrm{T}_{\mathrm{amb}}$ is the ambient temperature and $\mathrm{T}_{\text {fd-water }}$ is the water temperature in the pot, while the DNICalc_Avg is the measured hourly direct normal irradiance measured during the experiment.

The experiment proved that the developed parabolic solar cooker could achieve water boiling despite the low DNI available on the winter day that the experiment was carried out. Having confirmed the cooker could perform water boiling operation, various sensible cooking power analyses were then performed on the cooker, to understand the cooking power rating and effectiveness.

\section{Solar Cooker Performance Analysis}

An important criterion for solar cooker performance analysis, is the sensible cooking power or power rating or the solar cooker effectiveness measure. It is used to determine the magnitude of power required to boil a particular mass of water over a particular period. The sensible cooking analysis was performed in this study using 4 sets of water boiling experiments on 18th June, 2015 with water of mass $1.5 \mathrm{~kg}$ for each set. The experiments were carried out when the storage tank was fully charged (when the spiral cooker head temperature was the same as the average oil temperature) with no further charging (no oil was pumped up to the solar cavity heat receiver for further heating).

As seen in Fig. 9, the first water boiling took 13 minutes, the pot was emptied and fresh water was added and the experiment was repeated 3 times. The second, third and final sets of water took 17 minutes, 28 minutes and 38 minutes to boil respectively. The power consumed by each of the experiment equals $1,309 \mathrm{~W}, 915 \mathrm{~W}, 585 \mathrm{~W}$ and $410 \mathrm{~W}$ respectively.

Funk [12] developed several other methods to analyze and measure the cooking performance and efficiency of solar cookers. The advantage of these 


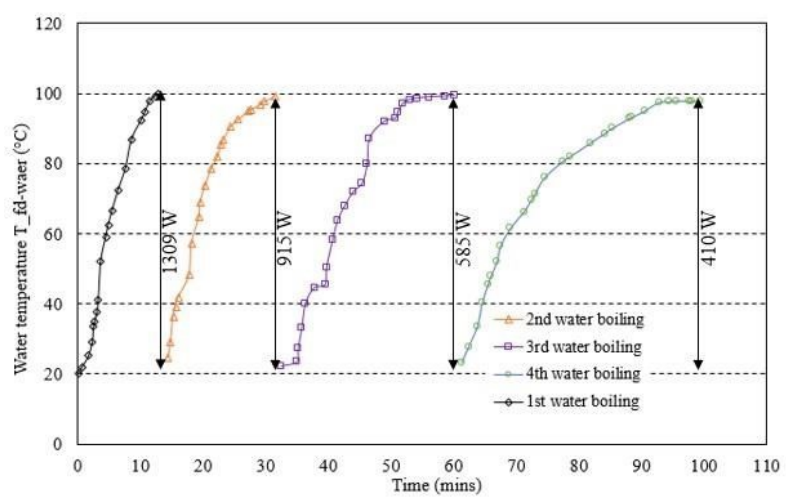

Fig. 9 Water boiling and power rating of the system.

standard cooking test analyses is that the result can be used to compare various cookers under different solar irradiation conditions. Some of the methods include the utilization efficiency, $\eta_{u}$ and characteristic boiling time, $t_{c}$. Utilization efficiency was expressed in terms of solar radiation, $I$, mass of water, $m$, the total time taken for water to reach boiling $\Delta t$, the solar collector aperture area $\mathrm{A}$.

$$
\eta_{u}=\frac{m c \Delta T}{I A \Delta t}
$$

The results from the experiments were also used to determine the characteristic boiling time of the system. The characteristic boiling time was determined using Eqs. (3) and (4), with reference solar insolation, $I_{\text {ref }}$, of $900 \mathrm{~W} / \mathrm{m}^{2}$ and specific boiling time $t^{b}$, as stated by Khalifa et al. [16].

$$
\begin{gathered}
t^{b}=\frac{\Delta t A}{m} \\
t_{c}=t^{b} \frac{I_{s}}{I_{\text {ref }}}
\end{gathered}
$$

The average characteristic boiling time for $3 \mathrm{~kg}$ water for this parabolic cooker is 3.1 minutes $/ \mathrm{kg}$, while the utilization efficiency is $39 \%$. These are highly good results based on the existing cooking standards. The overall calculated exergy efficiency for the system was also determined to be $0.05 \%$.

\section{Conclusion}

The study presented in this paper contributes to the limited existing literatures on indirect parabolic solar cookers. The results presented provide an extensive analysis of indoor parabolic cooking based on the international testing procedures for solar cookers.

The receiver design reduced heat loss by convection and radiation, and this was evident in the utilization efficiency recorded. The cooker also eliminated the user's exposure to sunshine.

The system cooks for a single family, and has the capability to be scaled up for industrial or communal cooking. The results from the study prove the viability of large scale solar cooking and serve as a decision instrument for policy-makers who may have interest in adopting solar cookers for various uses such as military camps cooking, refugee camps cooking, communal cooking and many other local uses.

\section{Acknowledgements}

The authors thank the STERG (Solar Thermal Energy Research Group) at the Department Mechanical and Mechatronics Engineering, Stellenbosch University for providing the research platform and the CRSES (Centre for Renewable and Sustainable Energy Studies) for funding the research.

\section{References}

[1] Craig, O., and Dobson, R. T. 2015. "Stand-Alone Parabolic Solar Cookers and Rural Industrialization in Southern Africa." In Proceedings of Southern African Solar Energy Conference (SASEC) 2015, 278-82.

[2] Department of Environmental Affairs. 2012. "Statistics South Africa, General Household Survey (Statistical release P0318).” State of Environment [Online]. Available: http://soer.deat.gov.za/1325.html.

[Accessed: 27-Jan-2015].

[3] Otte, P. P. 2013. "Solar Cookers in Developing Countries-What Is Their Key to Success?" Energy Policy 63: 375-81

[4] Craig, O. 2015. "A Stand-Alone Parabolic Dish Solar Cooker for African Conditions.” MEng thesis, Department of Mechanical and Mechatronic Engineering, Stellenbosch University.

[5] Panwar, N. L., Kaushik, S. C., and Kothari, S. 2012. "State of the Art of Solar Cooking: An Overview." Renew. Sustain. Energy Rev. 16 (6): 3776-85.

[6] Schwarzer, K., and da Silva, M. E. V. 2008. "Characterization and Design Methods of Solar Cookers." Sol. Energy 82 (2): 157-63 
[7] Muthusivagami, R. M., Velraj, R., and Sethumadhavan, R. 2010. "Solar Cookers with and without Thermal Storage-A Review." Renew. Sustain. Energy Rev. 14 (2): 691-701.

[8] Roth, P., Georgiev, A., and Boudinov, H. 2005. "Cheap Two Axis Sun Following Device." Energy Convers. Managt 46: 1179-92.

[9] Prinsloo, G. J., Dobson, R., and Schreve, K. 2014. "Automatic Positioner and Control System for a Motorized Parabolic Solar Reflector." Stellenbosch University.

[10] Stine, W. B., and Geyer, M. 2001. "Power from the Sun." [Online]. Available: Power from the sun.net. http://www.powerfromthesun.net/book.html. [Accessed: 15-Feb-2014].

[11] Craig, O., and Dobson, R. T. 2016. "Parabolic Solar
Cooker: Cooking with Heat Pipe vs. Direct Spiral Copper Tubes." In AIP Conference Proceedings, 160004.

[12] Funk, P. A. 2000. "Evaluating the International Standard Procedure for Testing Solar Cookers and Reporting Performance." Sol. Energy 68 (1): 1-7.

[13] El-Kassaby, M. M. 1991. "New Solar Cooker of Parabolic Square Dish: Design and Simulation." Renew. Energy 1 (1): 59-65.

[14] Amer, E. H. 2003. "Theoretical and Experimental Assessment of a Double Exposure Solar Cooker.” Energy Convers. Manag 44 (6): 2651-63.

[15] Kimambo, C. Z. M. 2007. "Development and Performance Testing of Solar Cookers.” J. Energy South. 18 (3): 41-51.

[16] Khalifa, M. A., Taha, M. M. A., and Akyurt, M. 1984. "An Energy Thrifty Solar Cooler-The Mina Oven.” Sol. Wind Technol.1 (2): 81-91. 